\title{
33. Procaine-Oil Blocking of the Globus Pallidus for the Treatment of Rigidity and Tremor of Parkinsonism \\ (Preliminary Report)
}

\author{
By Hirotaro Narabayashi and Teruo Okuma \\ Laboratory of Neurology and Psychiatry, School of Medicine, Tokyo University \\ (Comm. by S. Katsunuma, M.J.A., March 12, 1953)
}

Since our first stereotaxic instrument for operation on the human brain was completed in 1949 and the second modified type for the use in the supine position was devised in 1951, we have continued stereoencephalotomy as follows :

(1) Electrocoagulation of Nucleus medialis thalami for the treatment of the eretic type of feeblemindedness.

(2) Procaine-oil block of the Globus Pallidus for Athetosis, bilterai, double.

(3) Procaine-oil block of the Globus Pallidus for Parkinsonism.

In this paper, chiefly the experiences in Parkinsonism will be discussed.

Materials and Methods : Thirteen cases operated on, were treated formerly by Atropine sulfate (3 mg.-16 mg.), Scopolaminum hydrobromide or Artane, etc. without satisfactory improvement.

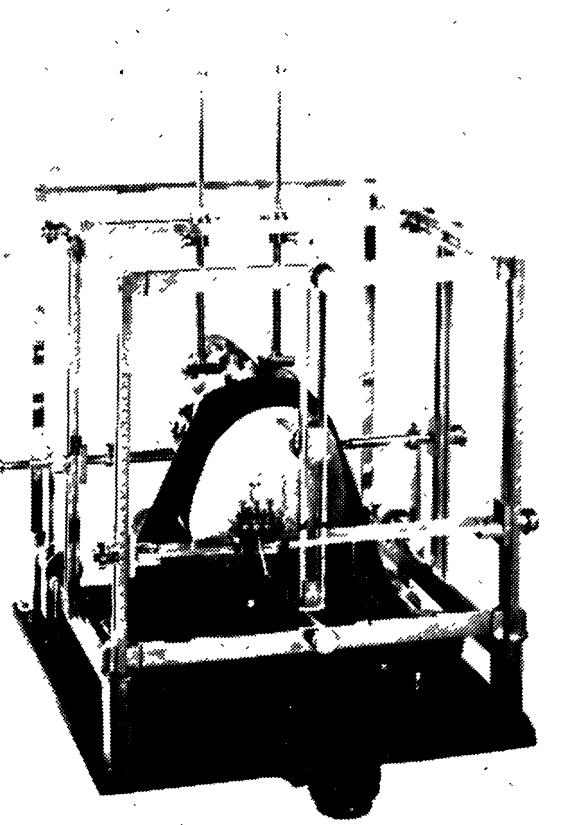

In the ten cases reported in this paper, a history of epidemic encephalitis was not obtained ex-

Fig. 1. 2nd model of stereoencephalotom, which should be used in the supine position

cept in cases 2 and 10, which was doubtful. Case 2 had high fever with delirium for two days, several years before the disease. Of ten cases, five were Hemiparkinsonism and five were bilateral Parkinsonism.

According to the coordinates of the Globus Pallidus as determined from pneumoencephalographic films, the needle should be inserted stereotaxically into the Nucleus.

Through this needle $(1 \mathrm{~mm}$. in diamater) the $10 \%$ Procaine-oil 
solution (mixture of nine parts oil and one part wax) is injected. This is considered to have a more concentrated and prolonged narcotic effect than Procaine aequous solution and to be safer than electrolysis.

Results and Considerations: Of the group of 13 patients operated upon, three were subjected to surgery too recently to permit an evaluation of the results of this procedure. Table I shows the results in ten cases.

Main symptoms were rigidity in cases $2,3,5$ and 10 ; tremor in cases 4 and 7 ; both rigidity and tremor in cases $1,6,8$ and 9 . We classified the grade of rigidity in four stages:

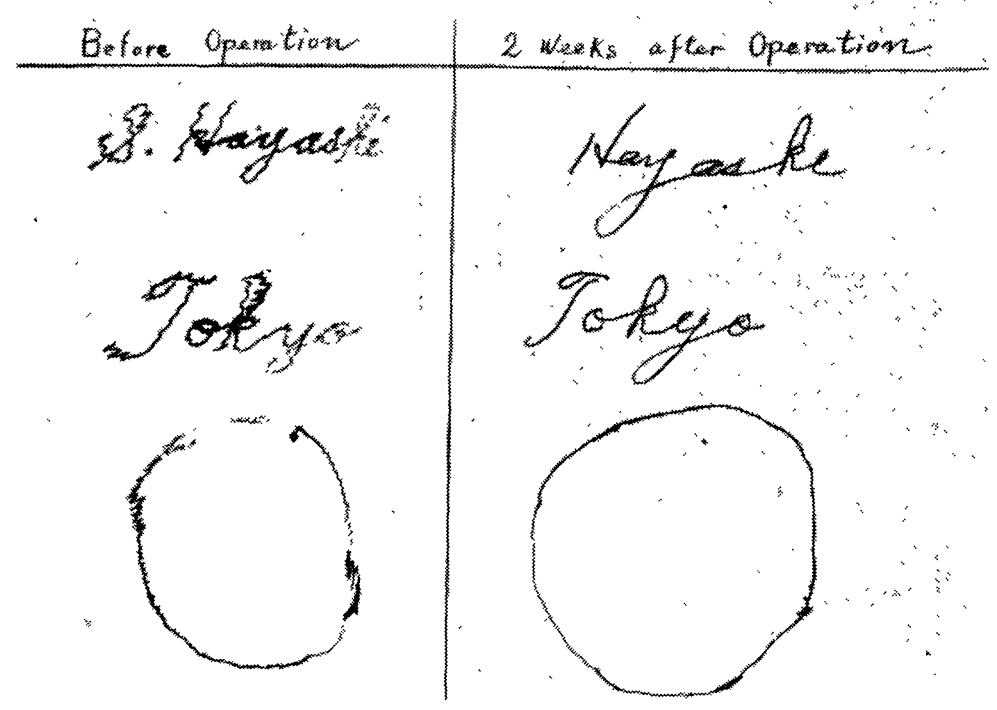

Fig. 2. Handwriting of case 4

(m) So rigid that the rapid apposition of thumb to forefinger, the finger touch, is less than 10 per $10 \mathrm{sec}$.

(H) The finger touch is less than 20 per $10 \mathrm{sec}$.

(H) The finger touch is less than 30 per $10 \mathrm{sec}$.

(+) The finger touch is more than 30 per 10 sec.

Tramor was characteristic, six spikes per sec. in electromyogram.

In every case, tremor and rigidity were abolished two or three minutes after injection. The change is dramatic and conspicuous. At the same time, it is most important to note that no undesirable side effects like palsy or disturbance of sensation following corticolysis were observed, provided the insertion was performed in the proper manner. Also we could find no hypotonia of the muscles after operation. Aimost every patient was able to feed himself, write and walk the next morning. Fig. 2 shows the handwriting of case 4 , which was markedly improved. A moving picture of each patient is made before and after operation. 


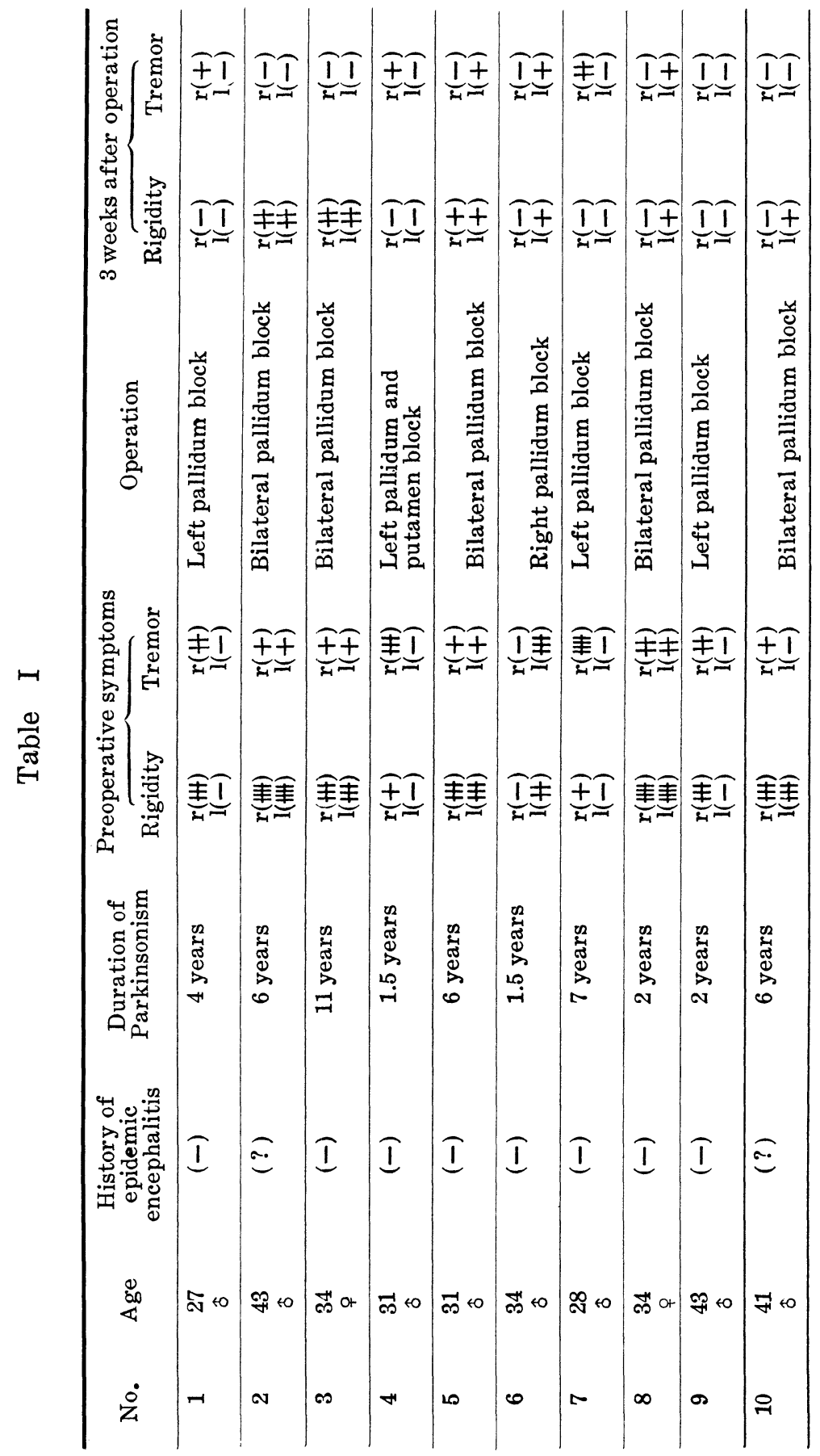


In general, slight rigidity or tremor tends to reappear in two or three months postoperatively. This, however, is not severe and does not give the patients as much disturbance compared with preoperative symptoms. This tendency of reappearance is seen more frequently in tremor, than in rigidity. When necessary, the operation should be repeated more thoroughly. In case 7 reoperation was tried two weeks after the first one. But the slight tremor began to reappear after ten days. The postoperative observation period is from one month to eleven months, and at present in all cases, especially in rigid type, the beneficial effects seem to be sustained.

The influence of this operation on the vegetative and psychic symptoms in cases of Parkinsonism is now being investigated.

\section{References}

1) Y. Uchimura and H. Narabayashi: Psychiatria et Neurologia Japonica, 52, 1951.

2) H. Narabayashi: Psychiatria et Neurologia Japonica, 54, 1953.

3) H. Narabayashi and T. Okuma: Psychiatria et Neurologia Japonica, 54, 1953.

4) E. A. Spiegel and H. T. Wycis: J. of International College of Surgeons, Oct., 1950. 